\title{
DEGRADAÇÕES AMBIENTAIS NO RIO COLÔNIA NO TRECHO URBANO DO MUNICÍPIO DE ITORORÓ, BAHIA
}

Ingrid Silva Rodrigues ${ }^{1}$, Cláudia Maria Reis Raposo Maciel², Alaor Maciel Júnior², Alice Almeida Diniz¹, Fernando Sérgio Souza Maciel ${ }^{3}$

1 Graduada em Ciências Biológicas, pela Universidade Estadual do Sudoeste da Bahia-UESB, Itapetinga, Bahia, Brasil. E-mail: ingridbels@hotmail.com 2 Professor Titular da UESB, Laboratório de Biologia.

Universidade Estadual do Sudoeste da Bahia - UESB, Itapetinga, Bahia, Brasil. 3 Graduado em Zootecnia, pela Universidade Estadual do Sudoeste da Bahia-

UESB, Itapetinga, Bahia, Brasil.

Recebido em: 03/10/2016 - Aprovado em: 21/11/2016 - Publicado em: 05/12/2016 DOI: 10.18677/EnciBio_2016B 110

\section{RESUMO}

O rio Colônia possui uma enorme relevância para a população de Itororó, BA, pois através dele é realizado o abastecimento de água potável para população urbana e rural do município. Este trabalho visa avaliar as principais degradações ambientais sofridas pelo rio Colônia, ao longo de seu percurso pela região urbana do município de Itororó, Bahia. Foram escolhidos pontos para as coletas dos dados, por meio de excursões e registros fotográficos, marcando os principais agentes impactantes do rio numa lista de checagem, tais como: a ausência de mata ciliar, o despejo de efluentes domésticos, o lançamento de resíduos sólidos agrícolas, a deposição de lixo, resíduos hospitalares, resíduos da construção civil, criatório de animais, construção na área de preservação permanente, abatedouro e construção de barragem. Observou-se que os principais impactos ambientais do rio Colônia foram oriundos de atividades principalmente como o despejo de esgotos domésticos sem tratamento prévio, percebido desde o ponto dois (P2) até o sete (P7), seguido da remoção da mata ciliar, fator este que esteve diagnosticado em todos os pontos exceto o seis (P6), além das construções civis na área de preservação permanente (APP) em P3, P4, P5 e P7. Não houve a constatação da presença de resíduos agrícolas e, nem de lixo hospitalar nas margens do rio Colônia nos pontos escolhidos para o estudo. Sendo assim, este estudo foi importante para um levantamento preliminar dos aspectos físicos que podem vir a degradar o rio, diante disto, seriam necessárias mais pesquisas específicas para analisar a qualidade da água.

PALAVRAS-CHAVE: check-list, impactos ambientais, preservação.

\section{ENVIRONMENTAL DEGRADATIONS OF THE COLÔNIA RIVER IN AN URBAN STRETCH, ITORORÓ, BAHIA}

\begin{abstract}
Colônia river has a huge relevance for the inhabitants from Itororó, BA, because through it is held the potable water supply to rural and urban areas of the municipality of that city. This study has the goal to evaluate the main environmental degradations occurred in the Colônia River, in the lower course urban area from Itororó, Bahia.
\end{abstract}


Points have been selected to data collection, during excursions, photographs, demarcating the leading causes of its degradation such as; lack of riparian areas, domestic and industrial effluent pesticides, waste disposal, hospital and civil construction waste, livestock farming, building in conservation areas, slaughtering and dam constructions. It was observed that the main environmental impacts in the Colônia river, in the city of Itororó, Bahia come from domestic sewage without previous treatment, realized from point two (P2) to point seven (P7), followed by riparian forest removal, this factor was diagnosed in all points except in the point six (P6) in addition to the buildings in permanent preservation areas (PPA) in P3, P4, P5 and P7. There was not observed the presence of agricultural waste nor hospital garbage in its riverbanks, in the points chosen for the research. As such, this study was important for a preliminary survey of the physical aspects which may degrade the river. Thus, it would be necessary more specific researches to analyze water quality.

KEYWORDS: check-list, environmental impacts, preservation.

\section{INTRODUÇÃO}

A água é um valioso recurso natural renovável, indispensável à vida, possuindo diversas utilidades. A diversificação desses usos tem gerado estresse hídrico, podendo causar até mesmo a escassez e, além disso, o crescente aumento da descarga de águas residuárias urbanas nos rios tem impactado esses ecossistemas, bem como as águas subterrâneas (TUNDISI, 2014).

KAZIMIRSKI et al. (2009) e OLIVEIRA (2009) afirmaram que a urbanização desordenada tem sido a maior responsável pelas grandes alterações ambientais e que os impactos são decorrentes da poluição e degradação ambiental causadas por ações humanas. Neste contexto, SANTOS et al., (2016) evidenciaram que a degradação das águas é uma questão grave, sendo mais incidente em regiões urbanas, onde grande quantidade de resíduos é lançada nos cursos hídricos de forma indiscriminada.

Em relação ao destino e utilização da água, MACHADO (2003) relatou que "preocupações suscitadas com a realidade dos recursos hídricos, isto é, as águas destinadas a usos, têm induzido, em todo o mundo, a uma série de medidas governamentais e sociais"; a meta é tornar viável o seguimento das diferentes atividades públicas e privadas que possuem como foco as águas doces, relacionadas com a qualidade de vida da população (MACHADO, 2001).

O rio Colônia é importante fornecedor de água para a população urbana e rural do município de Itororó, no Estado da Bahia, sendo fundamental, em alguns trechos, para agricultura familiar. Este rio possui importância histórica, social e cultural para o município, sendo utilizado para irrigação de hortaliças e pesca, significando, por muitas vezes, fonte de renda de diversas famílias (SANTOS \& OLIVEIRA, 2008).

Igualmente a outros rios do Brasil, o rio Colônia, por apresentar a característica de atravessar a zona urbana do município, vem sofrendo impactos negativos. Surge, assim, a necessidade de avaliar os tipos de degradações ambientais sofridas pelo rio, e também identificar as medidas mitigadoras a serem aplicadas, proporcionando informações que poderão ser utilizadas pelos gestores em projetos de recuperação (ALVES et al., 2012). Desta forma, objetivou-se diagnosticar as principais degradações ambientais sofridas pelo rio Colônia, ao longo de seu trecho urbano do município de Itororó, Bahia. 


\section{MATERIAL E MÉTODOS}

A pesquisa foi realizada no rio Colônia, no trecho urbano que atravessa o municipio de Itororó, Bahia (1507'01.3"S; 4003'57 .9"W). Foram selecionados, visualmente, sete pontos de coletas, denominados P1 a P7, locais onde os agentes causadores de degradação foram diagnosticados (Figura 1).

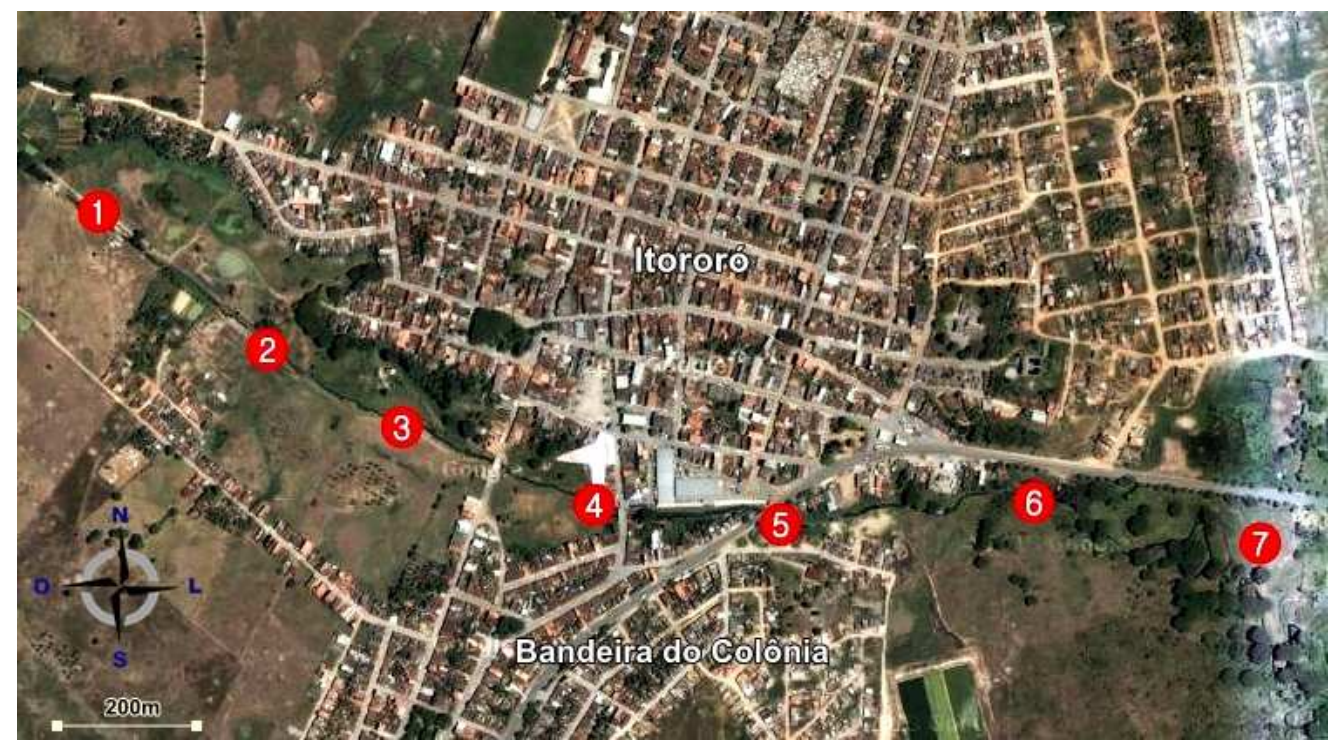

FIGURA 1. Imagem aérea do município de Itororó, BA, tendo em destaque, os pontos de coletas no rio Colônia (P01 a P07) utilizados neste estudo. (Fonte: Google Mapas / Satélite Landsat).

A área estudada abrangeu as divisas do município com o distrito de Bandeira, caracterizada pela presença de três pontes que delimitam o município. O percurso teve início após a última divisa, nas proximidades do bairro Colônia (P1), passando pelo centro do município de Itororó (P4 e P5) até a saída no sentido da rodovia Itabuna - Ilhéus, próximo ao desativado abatedouro de gado (P7).

A escolha dos pontos de coletas de dados foi realizada levando-se em consideração a distribuição dos agentes causadores de impactos ambientais, assim como a acessibilidade aos trechos do rio Colônia (KAZIMIRSKI et al., 2009). Essa seleção se deu por meio de excursões locais que possibilitaram descrever de forma qualitativa as atividades degradantes ao longo do rio Colônia, no trecho urbano de Itororó, BA, sendo cada ponto de coleta caracterizado e fotografado, considerando as condições físicas ambientais (ALVES et al., 2012).

Os períodos de coleta começaram no mês de outubro em $2013 \mathrm{com}$ o intuito de realizar o reconhecimento da área, sendo retomado nos meses de setembro e dezembro de 2014, onde foram feitas visitas periódicas, ou seja, semanais, quando os agentes degradantes foram registrados por meio de fotografias digitais (KAZIMIRSKI et al., 2009). Para a identificação das ações antrópicas degradantes, foi utilizado o método Check-list ou lista de checagem (CREMONEZ et al., 2014) que são listas padronizadas dos fatores ambientais, onde são apontados os impactos prováveis (PIMENTEL \& PIRES, 1992). Esse procedimento de listagem é um dos mais utilizados nas avaliações de impactos ambientais (ALVES et al., 2012).

Foram considerados 10 fatores causadores de degradações ambientais (ALVES et al., 2012), tais como: efluentes domésticos, ausência de mata ciliar, resíduos sólidos domésticos, resíduos hospitalares, resíduos agrícolas, resíduos 
industriais e de construção civil, criação de animais, construção de moradias na Área de Preservação Permanente (APP), abatedouro de animais e barramento da água. Após a checagem, as degradações ambientais causadas pelos agentes impactantes foram descritas e discutidas.

\section{RESULTADOS E DISCUSSÃO}

Foi observado que os principais impactos ambientais do rio Colônia foram originários principalmente do despejo de esgotos domésticos, sem tratamento prévio, aspecto este presente desde o ponto dois (P2), localizado depois da barragem de captação de água (P1), passando por todo o trecho urbanizado do município até o ponto sete (P7) situado no antigo abatedouro de gado da cidade. Estes fatores, juntamente com a inexistência total ou parcial da Mata Ciliar constatado em todos os pontos de análise exceto o ponto seis (P6), atrelado a construção de casas e prédios em área de preservação permanente em P3, P4, P5 e P7, consistiram os fatores de degradação mais frequentes em todo o trecho urbano do rio.

Os resíduos sólidos domésticos (lixo) ocorreram nos pontos cinco e dois; porém do tipo construção civil incidiu somente em um ponto de coleta (P5). O criatório de animais, abatedouro e barragem, estiveram presentes cada, em um ponto, sendo respectivamente: P4, P7 e P1. Não havendo registro de resíduos hospitalares nem agrícolas (Figura 2).

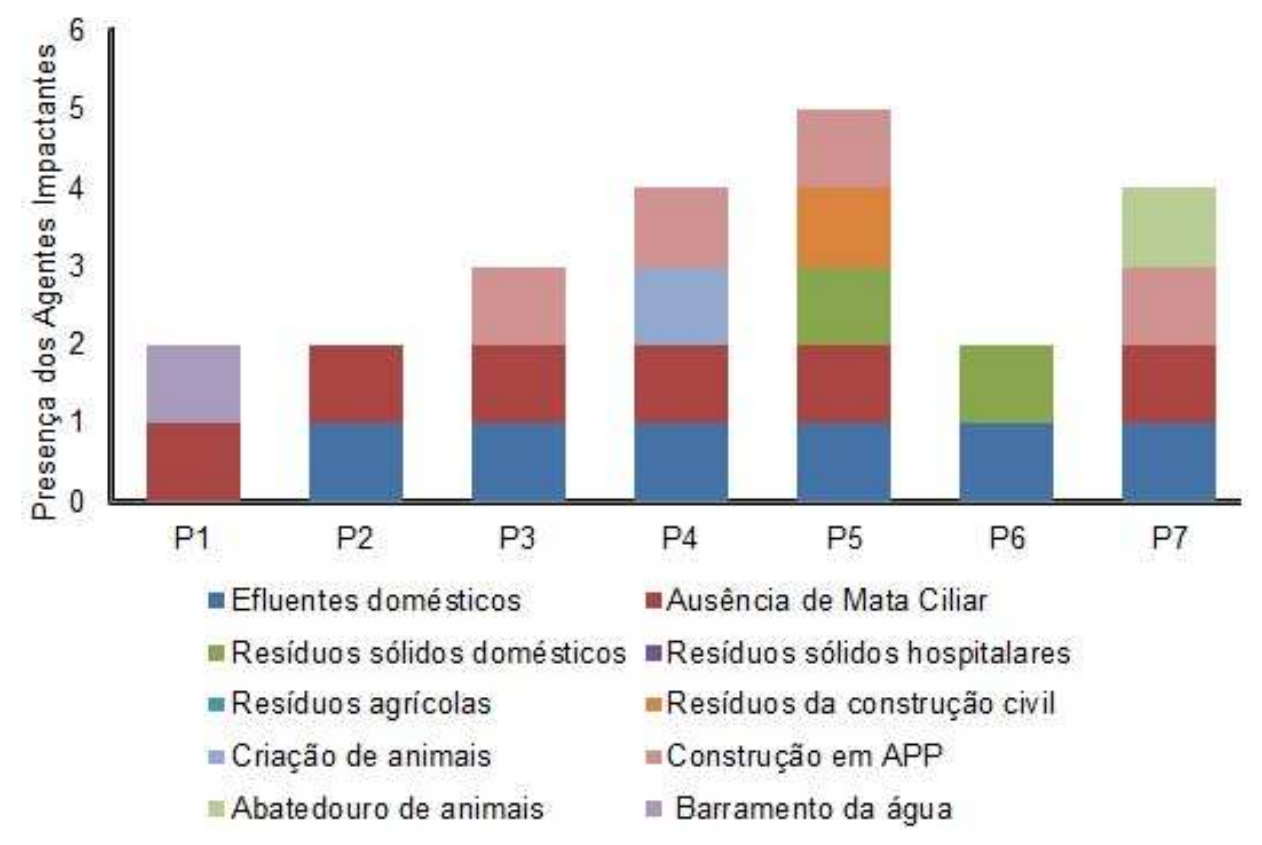

FIGURA 2. Distribuição dos agentes causadores de impacto ambiental por ponto de coleta no rio Colônia, em Itororó, Bahia em 2013/2014. (Fonte: Autores).

\section{Efluentes domésticos}

Durante as expedições foi constatado que o maior agente impactante foram os esgotos domésticos (Figura 3), pois o município não dispõe de grandes indústrias, capazes de escoar relevantes cargas de resíduos. Foi verificado, em todos os pontos estudados, que os esgotos domésticos eram despejados no rio sem nenhum tipo de tratamento, estando presentes, tanto na parte urbanizada percorrida pelo rio, 
como também no final do trajeto, ou seja, rodovia BA-130, no sentido Itabuna-Ilhéus. Aparentemente não foi verificado o descarte de esgoto no P7.

Este cenário de descuido com o destino dos esgotos gerados em Itororó pode ser explicado, pois os rios brasileiros assumiram um papel de escoamento de todos os tipos de dejetos domésticos, principalmente esgoto, pois as cidades se desenvolveram economicamente, contudo os seus rios não acompanharam o mesmo progresso perdendo em qualidade ambiental (ASSAD, 2013). O esgoto doméstico apresenta concentrações menores de matéria orgânica quando comparado com $o$ efluente industrial, mas favorece $o$ desenvolvimento $e$ multiplicação de bactérias heterotróficas aeróbias que acabam por consumir o oxigênio presente na água, além disso, possui coliformes fecais que são indicativos da presença de outros microrganismos transmissores de doenças (DEZOTTI, 2008).

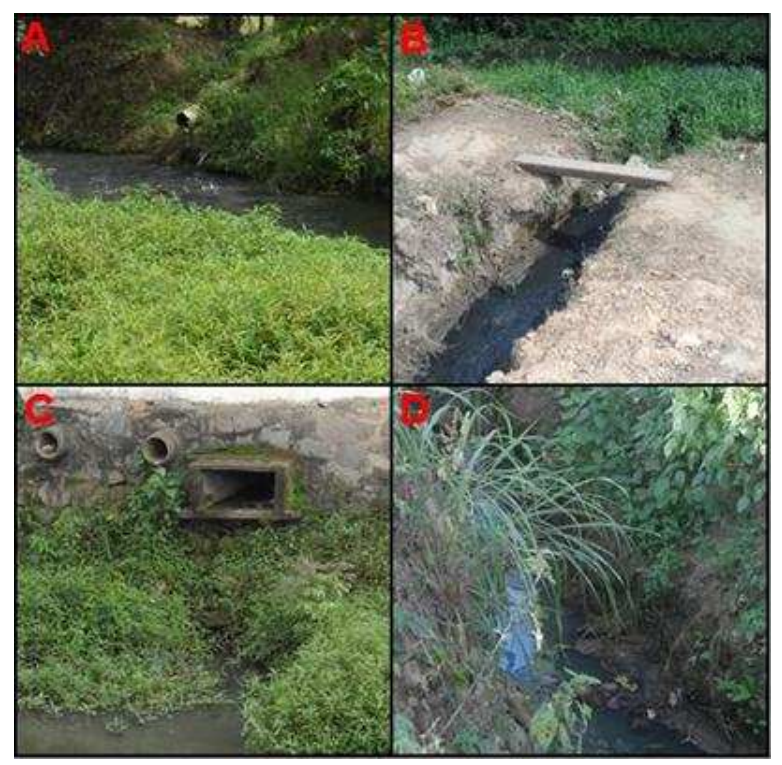

FIGURA 3. Focos de esgotos lançados no rio Colônia, em Itororó, BA, 2013. A) P2, B) P3, C) P5 e D) P6. (Fonte: Autores).

Especificamente, quando se trata de efluente doméstico, o município de Itororó, BA, dispõe de uma canalização destes resíduos, exceto em alguns novos bairros localizados em regiões periféricas. Contudo, como o observado no percurso entre o P2 ao P7, os efluentes domésticos são em sua totalidade despejados sem tratamento diretamente no rio Colônia, o que provavelmente provoca alterações na qualidade da água em diversos aspectos, pois se torna veículo de parasitas que causam doenças, prejudicando a população (VIEIRA, 2015).

Verificou-se claramente que o ponto cinco (P5) é o local que apresenta o maior número de focos de escoamento de esgotos domésticos, totalizando quatro, distribuídos entre tubulações e manilhas de vazão de efluentes. Este resultado era esperado por se tratar de um ponto localizado na região mais urbanizada e também por ficar próximo à feira-livre do município, ou seja, um local onde se produz grande quantidade de resíduos sólidos e líquidos.

Em Itororó seria necessário um plano de saneamento básico mais eficiente que evitasse a total perda da qualidade da água do rio Colônia (SANTOS \& OLIVEIRA, 
2008). Conforme o Art. $3^{\circ}$ da Lei $n^{\circ} 11.445$, de janeiro de 2007, que estabelece as diretrizes nacionais para o saneamento básico, considera o mesmo, como sendo "o conjunto de serviços, infraestruturas e instalações operacionais", que engloba o abastecimento de água potável, esgotamento sanitário, limpeza urbana e manejo de resíduos sólidos, drenagem e manejo das águas pluviais urbanas (BRASIL, 2007).

Segundo TUCCI (2005), assim como em Itororó a maioria das cidades brasileiras não possui tratamento de esgotos e lança os efluentes domésticos na rede de pluvial. É inegável que a implantação e instalação de uma estação para coleta e tratamento dos esgotos domésticos seriam uma solução plausível para essa problemática ambiental. Essa ação resultaria em melhoria da qualidade da água do rio Colônia, beneficiando diretamente à população em geral, que ganharia em saúde e qualidade de vida, especialmente os mais carentes que habitam as margens do rio (SANTOS \& OLIVEIRA, 2008).

\section{Ausência de Mata Ciliar}

A retirada da mata ciliar nas margens do rio Colônia está estritamente relacionada ao crescimento urbano e à pecuária. Com as condições favoráveis para o desenvolvimento da pecuária, grande parte das matas que existiam foram retiradas, sendo substituídas por pastagens como a espécie Panicum maximum, JUSSIEU (1789), (HASSEGAWA, 1996). PRIMO \& VAZ (2006) definiram mata ciliar como a vegetação que se estende às margens dos cursos d'água, protegendo os recursos hídricos, influenciando sua qualidade, mantendo seus atributos e equilíbrio de forma constante com a fauna e flora.

Em Itororó, nos pontos do rio que ainda existia algum vestígio de vegetação ripária, notou-se a presença de poucas árvores, dispostas na borda do curso d'água de forma espaçada, muitas das quais, disputam espaço com casas e edificações construídas nas margens.

No trecho estudado do rio Colônia já era perceptível o assoreamento em alguns pontos, especialmente no P5, onde o curso da água é mais raso e estreito. Este processo pode ser agravado pelo alto grau de deterioração ou pela inexistência da proteção vegetal do rio. Assim sendo, quanto maior o estado de degradação da mata ripária, menor será sua eficiência na retenção de sedimentos, devido à sua menor capacidade de reduzir a velocidade de transporte de partículas (OLIVEIRA et al., 2010).

Também foi percebido o início de processos erosivos nas margens do rio Colônia, especificamente em P1 e P3, onde o solo é desprovido de vegetação ciliar e, consequentemente, mais exposto à ação da água da chuva (Figura 4). Os processos erosivos nas margens de rios, acentuados ou não, pela retirada da mata ciliar, são manifestações mais perceptíveis da complexa readaptação da morfologia do canal em busca de uma nova estabilização e das modificações na dinâmica do sistema fluvial (HOLANDA et al., 2005; HOLANDA et al., 2009). Sabe-se que as matas ciliares podem atuar como redutor do assoreamento, sendo um importante suporte de segurança para o equilíbrio do ecossistema e suas relações essenciais (CASTRO et al., 2013). 


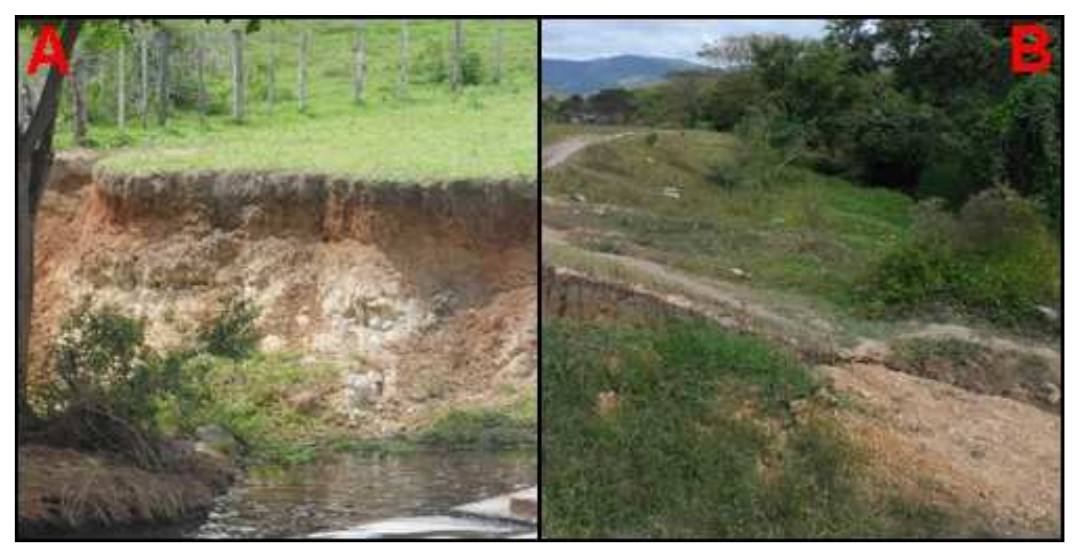

FIGURA 4. Erosão nas margens rio Colônia em Itororó, Bahia, sendo: A) P1 e B) P3. (Fonte: Autores).

De acordo com o Art. 4o da Lei oㅜ 12.651, de 25 de maio de 2012, que institui o novo Código Florestal Brasileiro, as áreas de preservação permanente (APP) podem ser definidas em zonas rurais ou urbanas, como sendo: "as faixas marginais de qualquer curso d'água natural perene e intermitente, excluídos os efêmeros, desde a borda da calha do leito regular". No que diz respeito à largura dos rios, são estipulados 30 metros, para os corpos d'água com menos de 10 metros de largura; 50 metros, para os que possuem de 10 a 50 metros; 100 metros, para os cursos d'água de 50 a 200 metros de largura; 200 metros, para os que tenham de 200 a 600 metros de largura, e 500 metros, para os rios que tenham largura superior a 600 metros (BRASIL, 2012).

\section{Resíduos sólidos domésticos}

Os resíduos sólidos domésticos foram encontrados em quantidade reduzida nos pontos observados, mas isso não implica que em outra área do rio Colônia, eles não possam ser achados. O despejo de resíduos sólidos domésticos às margens de ruas e cursos d'água pode provocar dentre outros, contaminação da água, assoreamento, enchentes, dispersão de patogenias, assim como a propagação dos vetores de transmissão de doenças (cães, gatos, ratos, baratas, moscas, vermes etc.), todos impactos somados a poluição visual, odores desagradáveis e contaminação do ambiente (MUCELIN \& BELLINI, 2008).

Os resíduos domésticos foram encontrados principalmente no P5, e P6. O fator que pode ter influenciado a disposição desses resíduos no local, é a proximidade da área a muitas moradias localizadas nas margens do rio Colônia e também limítrofe com a Praça Augustinho Costa Santos, onde é realizada a feira-livre do município de Itororó, apesar de haver a coleta do lixo doméstico e da feira livre pela prefeitura.

\section{Resíduos de construção civil}

Os resíduos da construção civil foram também observados no ponto 5 (P5) (Figura 5). São caracterizados por entulhos, restos de blocos, cimento, demolição de construções antigas e dentre outros dispostos na margem do rio. Segundo PASCOALIN-FILHO et al. (2013), "o ritmo imposto pelo crescimento econômico aos diversos setores da cadeia produtiva e o consumo, cada vez mais barato e intenso, têm causado a geração de vultosas quantias de resíduos sólidos urbanos (RSU).". Dentre os resíduos que compõem a massa de RSU gerada diariamente, grande parte destes se devem àqueles provenientes de atividades ligadas à construção civil. 
Os resíduos da construção civil ou demolição são também chamados de entulhos (CARNEIRO et al., 2001). A produção de uma grande quantidade desse material demonstra um enorme desperdício por trás dessas atividades desde a extração, transporte até a utilização na obra (OLIVEIRA \& MENDES, 2008).

De acordo com as diretrizes da Resolução CONAMA no 307 de 2002, os resíduos encontrados às margens do rio Colônia enquadram-se na Classe A. Estes, por sua vez, são caracterizados por serem recicláveis como os de aglomerados de construção, demolição, reformas e reparos de edifícios como: tijolos, blocos, telhas, placas de revestimento, argamassa e concreto.

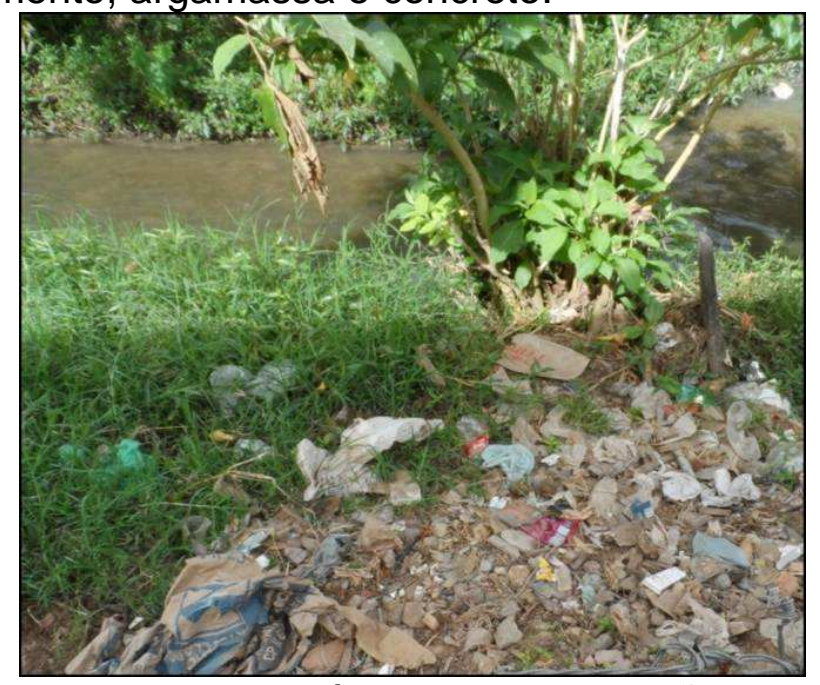

FIGURA 5. Resíduos de construção civil nas margens do rio Colônia (P05), Itororó, BA. (Fonte: Autores).

De maneira geral, esses resíduos da construção civil têm despertado o interesse dos pesquisadores que buscam não só reduzir a quantidade gerada, mas também torná-los úteis para potencial reutilização, reciclagem e manejo sustentável (PASCOALIN FILHO et al., 2013).

Sabe-se que a disposição errônea dos resíduos de construção civil gera muitos problemas sociais e ambientais como, por exemplo: contaminação do solo por gesso, tintas e solventes, além da rápida proliferação de insetos e outros vetores que contribuem para a complicação de problemas de saúde pública (MENDES et al., 2004; PASCHOALIN FILHO \& GRAUDENZ, 2012).

\section{Criatório de animais}

No município de Itororó, BA, a criação de animais foi registrada somente no ponto quatro. Pelo observado, tratava-se de criatório de galinhas ou porcos que estavam no terreno às margens do rio Colônia.

A presença de estábulos, pocilgas ou granjas é considerada potencialmente poluidora do ambiente, pois os detritos gerados dessas localidades podem conter microrganismos patogênicos que acrescem a poluição dos cursos d'água e elevam a Demanda Bioquímica de Oxigênio (DBO), modificando sua qualidade (ARAÚJO, 2006).

Os dejetos animais também podem ser empregados como fertilizantes agrícolas e por sua vez, pode ocorrer a degradação dos mananciais por microrganismos, além de minerais, esse processo ocorre principalmente através do 
acúmulo no solo e posteriormente com a lixiviação, podendo assim causar a contaminação dos lençóis freáticos por amônia e nitrato, vindo a comprometer a qualidade da água, resultando em uma expressiva mortalidade nos peixes (DONADIO \& BOGA, 2007).

\section{Construção de moradias na Área de Preservação Permanente (APP)}

As construções civis nas margens do rio Colônia (Figura 6) podem favorecer o aumento do despejo de resíduos neste local, seria correto que nesta área predominasse somente a vegetação nativa da região (ALVES et al., 2012), a Mata Atlântica (SANTOS \& OLIVEIRA). A urbanização em excesso é um fator que resulta em efeitos negativos do ponto de vista hidrológico, pois aumentam de forma perceptível os locais impermeabilizados ou concretados, favorecendo as enchentes durante o período chuvoso (KOBIYAMA et al., 2008).

As ocupações dessas áreas de APP são praticamente inevitáveis, visto que ainda uma grande parcela da população carente não possui recursos financeiros para morar em outros locais. Este fato associado à ineficiência dos governantes em aprovar áreas apropriadas para habitação geram como consequência o surgimento de moradias em áreas de preservação permanente que comprometem o curso do rio (BARBOSA \& FURRIER, 2013).

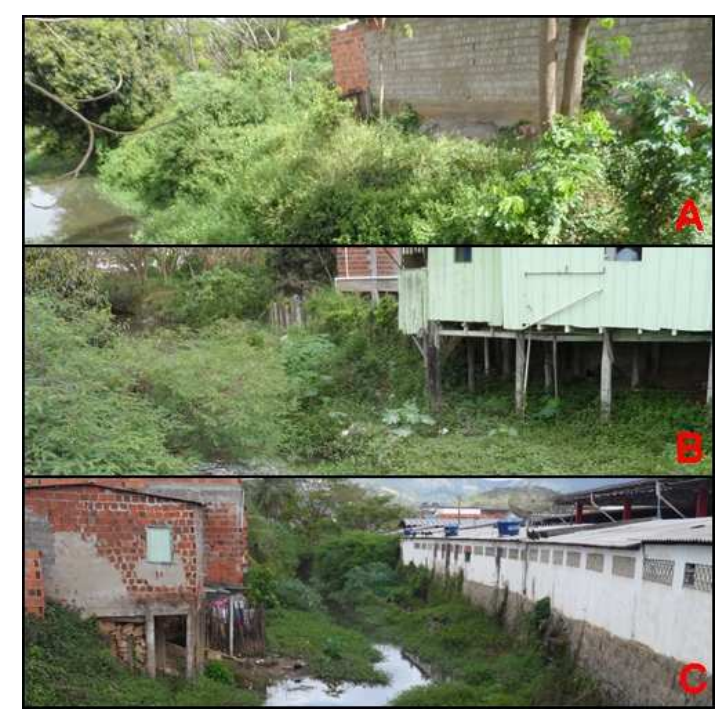

FIGURA 6. Construções (em área de preservação permanente (APPs) no rio Colônia, sendo A) P3; B) P4 e C) P5. (Fonte: Autores).

No rio Colônia é claramente perceptível que as suas áreas de borda deveriam está preservadas, mas foi visto que a vetação dá lugar às costruções de casas e edificações de diversos tipos, a inexistência total de vegetação em margens de rios é estritamente proibida segundo a legislação brasileira (TSUJII et al., 2014). Estas áreas são importantes não somente para o rio em Itororó, BA, mas também para outros ecossistemas aquáticos, pois auxilia na impregnação da água no solo, favorecendo a manutenção do lençol freático, impedindo o escoamento superficial de partículas sedimentares que causam poluição e assoreamento, além de 
providenciar sombra, aspecto este que favorece a regulação térmica da água (SALAMENE et al., 2012; TSUJIl et al., 2014).

\section{Abatedouro de animais}

No antigo abatedouro municipal de Itororó, localizado no P7, apesar de desativado, foram encontrados ossos de animais depositados nas margens do rio Colônia, que podem ser, possivelmente, de abates antigos. Entretanto o local ainda preserva 0 odor desagradável característico. Anteriormente, durante seu funcionamento, os resíduos líquidos do abatedouro, como sangue e visceras, atraiam grande quantidade de urubus, ratos e outros animais.

O abatedouro foi interditado pela Vigilância Sanitária, juntamente com o Ministério Público por conter inúmeras irregulares, dentre as quais a falta de higiene do estabelecimento, assim como o acondicionamento indevido da carne e o descarte de resíduos. De acordo ARAÚJO \& COSTA (2014), no Brasil, são comuns abatedouros bovinos em situações precárias de funcionamento, apesar das normas existentes para o funcionamento adequado desses estabelecimentos.

Os impactos relacionados com os abatedouros de animais estão restritos aos despejos ou resíduos procedentes das distintas etapas do processamento da carne (ROCHA, 2008). No caso dos efluentes líquidos, esses podem contaminar o solo e as águas superficiais, como também subterrâneas, e finalmente o odor gerado pela decomposição da matéria orgânica, descartada de forma incorreta, que se configura como um fator indesejável (TAVARES \& WEBER, 2012).

Os abatedouros públicos de bovinos constituem uma atividade rentável economicamente, mas também são grandes geradores de resíduos, consistindo uma grande fonte puluidora, podendo causar danos ambientais e a saúde das pessoas, essa situação ocorre quando não atendem a legislação ambiental (ARAÚJO \& COSTA, 2014).

\section{Construção de barramento da água}

A barragem localizada no primeiro ponto incide na área onde é realizada a captação de água, especificamente na saída do município, após o bairro Colônia (Figura 7). O local era o mais "preservado" de todo percurso do rio se comparado com os demais pontos observados, levando-se em consideração, principalmente, o despejo de esgotos domésticos. É importante salientar que água não apresentou o odor desagradável característico dos outros pontos de observação, sendo a mesma utilizada para a irrigação de plantações pela população ribeirinha (MELLO, 2013).

Segundo o funcionário da empresa que realiza o abastecimento de água para o município, e que fez o acompanhamento neste trajeto do rio Colônia, o barramento é positivamente fundamental para o fornecimento de água para os habitantes de Itororó, onde o mesmo se faz possível até mesmo nos períodos de escassez de chuvas, típico de algumas regiões do Nordeste (MELLO, 2013). No período anterior a sua construção, a captação era realizada de forma limitada, somente com o auxílio de uma bomba hidráulica. Porém, com o crescimento do município e aumento do número de residências, houve a necessidade da construção do barramento, uma vez que, além da vazão da água ter diminuído, a demanda aumentou expressivamente. 


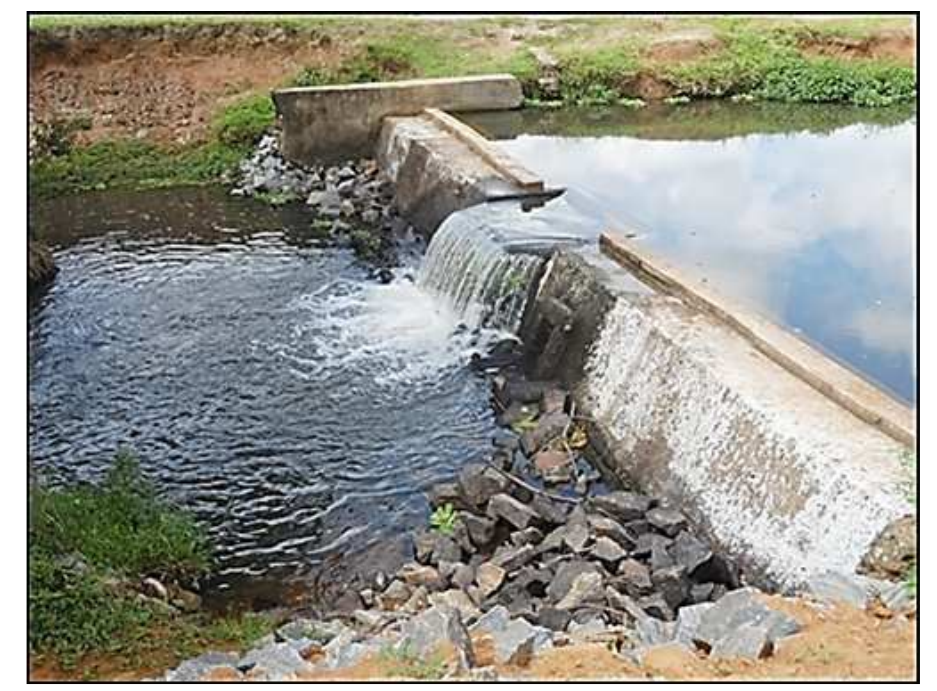

FIGURA 7. Barragem de captação de água do Sistema Autônomo de Água e Esgoto (SAAE) no rio Colônia, em Itororó, Bahia (P1). (Fonte: Autores).

Dessa forma, a barragem é importante, pois sem esta, a captação de água estaria comprometida e não atenderia a demanda atual. Este tipo de construção segundo MELLO (2013) pode trazer outros benefícios como a defesa contra inundações, atuando no controle das cheias do rio, e também para atividades de recreação e paisagismo. Entretanto, o barramento e acumulação da água causam também impactos negativos, como movimentos de terras, erosão do solo, assoreamento e mudança no escoamento da água (BRASIL, 2005). Em Itororó, seriam necessários estudos mais específicos para identificar se existência da barragem, exerce algum tipo de impacto negativo sobre a dinâmica do rio Colônia.

\section{CONCLUSÕES}

Pode-se perceber que os principais impactos ambientais do rio Colônia, em Itororó, Bahia, são oriundos de atividades como o despejo dos esgotos domésticos e lixo, juntamente com a retirada gradativa da mata ciliar e as construções civis nas margens do rio.

O método Check-list (lista de checagem) utilizado para esta pesquisa de Avaliação dos Impactos Ambientais-AIA, em Itororó mostrou-se satisfatório, pois foi de fácil execução e custo barato, além de ter demostrado resultados rápidos à um curto intervalo de tempo, listando de forma preliminar os agentes causadores de perturbação ambiental visíveis no rio Colônia e em suas margens. No entanto seria necessária a realização de mais estudos que mostrassem as qualidades físicas, químicas e biológicas (quantificação de microrganismos patogênicos) da água do rio. $\mathrm{E}$ em que estes aspectos ambientais podem interferir na biota aquática e na qualidade de vida da população local.

Por tudo isso, é esperado que este estudo possa ser levado ao conhecimento da população de Itororó e governantes locais sobre a situação ambiental do rio colônia, e que os mesmos possam se interessar não somente pelo estado de degradação do principal rio que abastece Itororó, mas também que encontrassem alternativas para melhorar o atual estado, sendo o mesmo fundamental para a 
sobrevivência de muitas famílias, inclusive também da zona-rural, utilizado para pesca e irrigação.

\section{REFERÊNCIAS}

ALVES, T. L. B.; LIMA, V. L. A.; FARIAS, A. A. Impactos Ambientais no Rio Paraíba na área do município de Caraúbas - PB: área contemplada pela integração com a bacia hidrográfica do rio São Francisco. Caminhos de Geografia, v. 13, p. 160-173, 2012. Disponível em: <http://www.seer.ufu.br/ index.php/caminhosdegeografia/article/viewFile/16758/10524> .doi: 16758/10524

ARAÚJO, P. P. P; COSTA, L. P. Impactos ambientais nas atividades de abate de bovinos: um estudo no matadouro público municipal de Caicó-RN. Revista Halos. 2014. Disponível em: <http://fcst.edu.br/site/impactos-ambientais-nas-atividades-deabate-de-bovinos-um-estudo-no-matadouro-publico-de-caicorn/> Acesso: 05/04/2016.

ASSAD, L. Cidades nascem abraçadas a seus rios, mas thes viram as costas no crescimento. Revista Ciência e Cultura, v. 65, n 2, p. 6-9, 2013. Disponível em:<http://cienciaecultura.bvs.br/scielo.php?pid=S0009-67252013000200003\& script=sci_arttext>.doi: 0009-67252013000200003

ARAÚJO, L. A. Degradação ambiental nos rios do estado do Rio de Janeiro. Anuário do Instituto de Geociências, v. 29, n. 2, p. 236-237, 2006. Disponível em: $<$ http://ppegeo.igc.usp.br/scielo.php?script=sci_arttext\&pid=S0101-9759200600 0200023\&lng=pt\&nrm=iso > .doi: 0101-97592006000200023

BARBOSA, T. S.; FURRIER, M. Ocupações Irregulares e Impactos Sócio-Ambientais às Margens do Rio Sanhauá, Paraíba / Brasil. Revista Percurso - Nemo, v. 5, n. 2, p. 91-107, 2013. Disponível em: < http://periodicos.uem.br/ojs/index.php/Percurso/article/view/21591>. doi: http://dx.doi.org/10.4025/revpercurso.v5i2.21591

BRASIL, Ministério da Integração Nacional. Secretaria de Infraestrutura Hídrica. Unidade de Gerenciamento do Proágua/Semiárido. Diretrizes ambientais para projeto e construção de barragens e operação de reservatórios. Brasília: Bárbara Bela Editora Gráfica e Papelaria Ltda., 2005.

BRASIL. Lei no 11.445, de 05 de janeiro de 2007. Estabelece diretrizes nacionais para o saneamento básico; altera as Leis nos 6.766, de 19 de dezembro de 1979, 8.036, de 11 de maio de 1990, 8.666, de 21 de junho de 1993, 8.987, de 13 de fevereiro de 1995; revoga a Lei no 6.528, de 11 de maio de 1978; e dá outras providências. Disponível em:<http://www.planalto.gov.br/ccivil_03/_Ato20072010/2007/Lei/L11445.htm>

BRASIL. Lei no 12.651, de 25 de maio de 2012. Dispõe sobre a proteção da vegetação nativa; altera as Leis nos 6.938, de 31 de agosto de 1981, 9.393, de 19 de dezembro de 1996, e 11.428, de 22 de dezembro de 2006; revoga as Leis nos 4.771 , de 15 de setembro de 1965, e 7.754, de 14 de abril de 1989, e a Medida Provisória no 2.166-67, de 24 de agosto de 2001; e dá outras providências. Diário 
Oficial da República Federativa do Brasil, Brasília, DF, 25 mai 2012. Disponível em:< http://www.planalto.gov.br/ccivil_03/_ato2011-2014/2012/lei//12651.htm>

CARNEIRO, A. P.; BURGOS, P. C; ALBERTE, E. P. V. Uso do agregado reciclado em camadas de base e sub-base de pavimentos. Projeto Entulho Bom. Salvador: EDUFBA/Caixa Econômica Federal, p. 188-227, 2001.

CASTRO, N. M.; CASTRO, M. R.; SOUZA, C. P. A Importância da Mata Ciliar no contexto da conservação do solo. Revista Eletrônica da Faculdade de Araguaia, v. 4, p. 230-241, 2013.

CREMONEZ, E. F.; CREMONEZ, P. A.; FEROLDI, M.; CAMARGO, M. P.; KLAJN, F. F.; FEIDEN, A. Avaliação de impacto ambiental: metodologias aplicadas no Brasil. Revista Monografias Ambientais - REMOA, v. 13, n. 5, p. 3821-3830, 2014. Disponível em: <https://periodicos.ufsm.br/remoa/article/download/14689/pdf>. doi:10.5902/2236130814689

DEZOTTI, M. Processos e Técnicas para o controle ambiental de Efluentes Líquidos. Série Escola Piloto de Engenharia Química. COPPE/UFRJ. Rio de Janeiro: ed E-papers, 360p. 2008.

DONADIO, A. P.; BOGA, P. B. F. A produção animal industrial e a questão ambiental. In: Congresso Internacional de Direito Ambiental, 2007, São Paulo. Meio ambiente e acesso à justiça: fora reserva legal e APP. São Paulo: Impressa oficial do Estado de São Paulo, v. 3. p. 483-492, 2007.

HASSEGAWA, W. R. A crise da economia pecuária bovino-extensiva da microrregião pastoril de Itapetinga: subordinação, conflitos e mudanças nas relações e meios de produção nos últimos 30 anos. Dissertação (Mestrado em Extensão Rural) - Universidade Federal da Bahia, 220p. 1996.

HOLANDA, F. S. R.; SANTOS, L. G. C.; SANTOS, C. M. S.; CASADO, A. P. B.; PEDROTTI, A. Riparian fragments affected by bank erosion in the Lower São Francisco River, Northeastern Brazil. Revista Árvore, v. 29, n. 2, p.148-152, 2005. Disponível em: <http://dx.doi.org/10.1590/S0100-67622005000200016>. doi: 10.1590/S0100-67622005000200016.

HOLANDA, R. S. F.; BANDEIRA, A. A.; ROCHA, P. I.; ARAÚJO FILHO, N. R.; RIBEIRO, F. L.; ENNES, A. M. Riverbank erosion control at streams margin: from empiricism to soil bioengineering technique. Revista Ra'e Ga- O Espaço Geográfico em Análise, n. 17, p. 93-101, 2009. Disponível em: $<$ http://dx.doi.org/10.5380/raega.v17i0>.doi:10.5380/raega.v17i010.5380/raega.v35i0

KAZIMIRSKI, V. V.; VANZ J.; ANGRA, D. C.; NECKEL, A. Diagnóstico das degradações ambientais ocorridas no rio Marau - Município de Marau RS. Enciclopédia Biosfera, v. 8, p. 1- 15, 2009. Disponível em:< www.conhecer.org.br/enciclop/2009B/diagnostico\%20das\%20degradacoes.pdf>. Acessoem: 25/10/2016. 
KOBIYAMA, M.; MOTA, A. A.; CORSEUIL, C. W. Recursos Hídricos e Saneamento. Curitiba: Editora Organic Trading, 160p. 2008.Disponível em:< http://www.labhidro.ufsc.br/Artigos/recursos_hidricos_saneamento.pdf >. Acesso em: 25/10/2016. Disponível em: <http://www.labhidro.ufsc.br/Artigos/recursos_hidricos_saneamento.pdf $>$.Acesso em: 25/10/2016.

MACHADO, C. J. S. Experiências Internacionais de Gestão de Águas Interiores: Uma Análise Comparada com o Arcabouço Jurídico Brasileiro. Revista Forense Eletrônica (Suplemento), v. 356, agosto, 2001.

MACHADO, C. J. S. Recursos hídricos e cidadania no Brasil: limites, alternativas e desafios. Ambiente \& sociedade, Campinas, v. 6, n. 2, p. 121-136, 2003.

MELLO, F. M. A importância dos reservatórios formados por barragens. Revista Newsletter CBDB-ARTIGO, p. 1-3, 2013. Disponível em: <http://www.cbdb.org.br/site_antigo_2013/img/47artigo.pdf>. Acesso: 19/10/2016.

MENDES, T. A.; REZENDE, L. R.; OLIVEIRA, J. C.; GUIMARÃES, R. C.; CAMAPUM DE CARVALHO, J.; VEIGA, R. Parâmetros de uma Pista Experimental Executada com Entulho Reciclado. In: 35ª Reunião Anual de Pavimentação, Rio de Janeiro. Anais. 211 p., 2004.

MUCELIN, C. A.; BELLINI, M. Lixo e impactos ambientais perceptíveis no ambiente urbano. Revista Sociedade \& Natureza, v. 20, p 111-124, 2008.

OLIVEIRA, E. G.; MENDES, O. O Gerenciamento de resíduos da construção civil e demolição: estudo de caso da resolução 307 do CONAMA. Universidade Católica de Goiás, Goiânia, 2008.

OLIVEIRA, A. C.; KLIEMANN, J. H.; CORRCHEL, V.; SANTOS, V. C. F. Avaliação da retenção de sedimentos pela vegetação ripária pela caracterização morfológica e físico-química do solo. Revista Brasileira de Engenharia Agrícola e Ambiental, v. 14, n. 12, p. $1281-1287,2010$.

PASCOALIN FILHO. J. A.; DIAS, A. J. G.; CORTES, P. L.; DUARTE, E. B. L. Manejo de resíduos de demolição derados durante obras da arena de futebol Palestra Itália (Allianz Parque) localizada na cidade de São Paulo/Brasil. Revista Holos, v. 6, p 7391, 2013.

PASCHOALIN FILHO, J. A.; GRAUDENZ, G. S. Destinação irregular de resíduos de construção e demolição (RCD) e seus impactos na saúde coletiva. Revista de Gestão Social e Ambiental, v. 6, n.1, p. 127-142, 2012.

PIMENTEL, G. \& PIRES, H. S. Metodologias De Avaliação De Impacto Ambiental: Aplicações e Seus Limites. Revista Administração Pública, v. 26, n. 1, p. 56-68, 1992.

PRIMO, C. D.; VAZ, S. M. L. Degradação e Perturbação Ambiental em Matas Ciliares: Estudo de Caso do Rio Itapicuru-Açu em Ponto Novo e Filadélfia Bahia. 
Diálogos \& Ciência - Revista Eletrônica da Faculdade de Tecnologia e Ciências, n. 7, p. 1-11, 2006.

RESOLUÇÃO CONAMA, № 303, DE 20 DE MARÇO DE 2002. Disponível em: <http://www.mma.gov.br/conama/>. Acesso em: dezembro de 2014.

ROCHA, M. R. Avaliação da eficiência no tratamento de efluentes líquidos em frigoríficos. UDC: Foz do Iguaçu, p 1-73, 2008.

SALAMENE, S.; FRANCELINO, M. R.; VALCARCEL, R.; LANI, J. L.; SÁ, M. M. F. Estratificação e caracterização ambiental da área de preservação permanente do Rio Guandu / RJ. Revista Árvore, v. 35, n. 2, p. 221-231, 2012.

SANTANA, A. F. de; SANTANA, F. F.; MATA, H. T. C.; SANTANA, L. F. Turismo como vetor de desenvolvimento local sustentável: o caso do FESTSOL. In: Fernando Rios do Nascimento. (Org.). 40 ANOS DO CURSO DE ECONOMIA (MEMORIA). Ilhéus-Bahia: Editus, v. 1, p. 1-628, 2005.

SANTOS, J. C.; CONRADO, D. M.; NUNES-NETO, N. F. Questões sociocientíficas no ensino fundamental de ciências: uma experiência com poluição de águas. Indagatio Didactica, v. 8, p. 1051-1067, 2016.

SANTOS, R. M. S.; OLIVEIRA, N. G. Inatividade de sistema de esgotamento sanitário: um estudo de caso no município de Itororó-Bahia. Revista Saúde.Com, v. 4(1): p. 85-94, 2008.

TAVARES, M. E.; WEBER, I. M. Impactos ambientais e tratamentos gerados pelos efluentes de abatedouros de bovinos. p 1-17, 2012.

TUCCI, C. E. M. Programa de drenagem sustentável: apoio ao desenvolvimento do manejo das águas pluviais urbanas - Versão 2.0. Brasília: Ministério das Cidades, 2005.

TUNDISI, J. G (Ed.) Recursos hídricos no Brasil problemas desafios e estratégias para o futuro. Rio de Janeiro: Academia Brasileira de Ciências, 76p 2014.

TSUJII, P. K.; RIBEIRO, A. C. C.; CARNEIRO, V. A.; MELO NETO, C. S.; GONÇALVES, B. B. Uso e ocupação das áreas de preservação permanentes no sudoeste goiano. Revista de Geografia (Recife), v. 31, p. 43 -60, 2014.

VIEIRA, L. R.; VIEIRA, L. R.; VESTENA, S. A Questão do saneamento no espaço rural: uma abordagem ambiental em três localidades rurais no município de Nova Palma, RS. Revista Eletrônica em Gestão, Educação e Tecnologia Ambiental, v. 19 , n. 1, p. 38-50, 2015. Disponível em: <http://cascavel.ufsm.br/revistas/ojs2.2.2/index.php/reget/article/view/15379/pdf>. doi: 10.5902/22361170. 